\title{
PROFILE OF CULTURE POSITIVE ENTERIC FEVER IN CHILDREN ADMITTED IN A TERTIARY CARE HOSPITAL
}

Mullainathan Sucindar ${ }^{1}$, Seshanganur Sitaraman Kumaran ${ }^{2}$

${ }_{1}^{1}$ Assistant Professor, Department of Paediatrics, Sri Lakshmi Narayana Institute of Medical Sciences (SLIMS), Puducherry.

${ }^{2}$ Assistant Professor, Department of Paediatrics, Sri Lakshmi Narayana Institute of Medical Sciences (SLIMS), Puducherry.

ABSTRACT
BACKGROUND
According to literature, there are only few studies and also only one Indian prospective study from South India available on culture
positive enteric fever, hence this study was undertaken to provide a data about entire profile of culture positive enteric fever in
children from South India, particularly Puducherry.
The aims of this study are to assess-
a) Proportion of culture positive enteric fever cases among children aged 6 months to 18 years, admitted with fever of $\geq 3$ days in a
tertiary care hospital,
b) Their clinical and laboratory profile,
c) Culture sensitivity pattern,
d) Response to antibiotics,
e) Complications.

\section{MATERIALS AND METHODS}

This was a prospective observational study done between June 2016 and May 2017 at SLIMS, Puducherry. Total study population was 51. They were included in the study after getting informed consent and the following data were collected: a) Age, sex and socioeconomic details; b) Symptoms; c) Signs; d) Laboratory parameters; e) Antibiotic sensitivity pattern; f) Treatment and clinical outcomes. All the data were statistically analysed by using SPSS software.

\section{RESULTS}

In our study, $58.82 \%$ were $<5$ years. The predominant symptoms seen are high grade fever in 51 (100\%), vomiting in 27 (52.94\%), anorexia in $22(43.14 \%)$ and diarrhoea in 20 (39.22\%). The predominant signs seen are isolated hepatomegaly in 34 (66.66\%), hepatosplenomegaly in $11(21.57 \%)$ and coated tongue in $10(19.61 \%)$. Majority of the population had normal total counts, high CRP and elevated SGOT and SGPT. Salmonella typhi was the major isolate in Blood Culture and Sensitivity and all strains were sensitive to ceftriaxone. Overall, Mean (SD) time for defervescence of fever was 3.86 ( \pm 2.12 ) days and Mean (SD) hospital stay duration was 6.84 ( \pm 2.09 ) days. Only one complication (consolidation) and no death were seen in our study.

\section{CONCLUSION}

Enteric fever should be suspected when there is high CRP, normal WBC and Platelet counts in a child with $\geq 3$ days fever with isolated hepatomegaly/ hepatosplenomegaly. Blood culture is the gold standard diagnostic test. Antibiotic sensitivity pattern showed re-emergence of strains with high sensitivity to first line antibiotics like Ampicillin, Chloramphenicol and Cotrimoxazole. Nalidixic acid resistance was observed in all isolates. All the cultures were sensitive to Ceftriaxone and it was used as first line intravenous antibiotic for enteric fever with good outcome.

\section{KEYWORDS}

Culture Positive Enteric Fever; Clinical and Laboratory Profile; Clinical Outcomes.

HOW TO CITE THIS ARTICLE: Sucindar M, Kumaran SS. Profile of culture positive enteric fever in children admitted in a tertiary care hospital. J. Evolution Med. Dent. Sci. 2017;6(88):6112-6117, DOI: 10.14260/jemds/2017/1328

\section{BACKGROUND}

Enteric fever is one of the common causes of fever in children with varied presentations. We have observed that many studies are available in general on enteric fever, but only few studies $1,2,3,4$ mentioned about profile of culture positive enteric fever in the medical literature. Since there is paucity of studies 5,6

'Financial or Other Competing Interest': None.

Submission 15-09-2017, Peer Review 25-10-2017,

Acceptance 31-10-2017, Published 06-11-2017.

Corresponding Author:

Seshanganur Sitaraman Kumaran,

No. 204, Nakkeeran New Street,

Seshanganur, Viluppuram-6055501.

E-mail:drkumaran83@gmail.com

DOI: $10.14260 /$ jemds/2017/1328
Available on culture positive enteric fever and also only one Indian prospective study ${ }^{1}$ from South India, this study was undertaken to provide a data about entire profile of culture positive enteric fever in children from South India, particularly Puducherry. Since culture positive cases can give true picture of entire spectrum and outcome of enteric fever, the study was confined to culture positive enteric fever cases alone.

\footnotetext{
Aims and Objectives

To assess- a) Proportion of culture positive enteric fever cases among children aged 6 months to 18 years, admitted with fever of $\geq 3$ days in a tertiary care hospital; b) Their clinical and laboratory profile; c) Culture sensitivity pattern, d) Response to antibiotics and e) Complications.
} 


\section{MATERIALS AND METHODS}

This was a prospective observational study done during one year (June 2016 - May 2017) at Sri Lakshmi Narayana Institute of Medical Sciences (SLIMS), Puducherry, after Ethical clearance obtained from Ethical Committee, SLIMS, Puducherry. The study population was Children aged 6 months to 18 years admitted with fever of $\geq 3$ days in a tertiary care hospital, proved to have culture positive enteric fever. Children with Enteric fever associated with coinfections or those who are managed outside are excluded from the study. Sample size was calculated at power of $80 \%$ and alpha error of 0.05 ; required sample size was 50 based on previous study. ${ }^{5}$

All children presenting with fever of $\geq 3$ days were subjected to undergo following investigations: $\mathrm{Hb}$ (Haemoglobin), TLC (Total Leukocyte Count), PLC (Platelet count), CRP (C-Reactive Protein), LFT (Liver Function Test), WIDAL, Blood C and S (culture and sensitivity), USG Abdomen and CXR (Chest X-Ray). Once blood culture was positive for salmonella, they were included in the study after getting informed consent and the following data were collected: a) Age, sex and socioeconomic details, b) Symptoms, c) Signs, d) Laboratory parameters, e) Antibiotic sensitivity pattern, and f) Treatment and clinical outcomes.

Investigations detail: $\mathrm{Hb}$, TLC and PLC were done by automated haemogram analyser. CRP was done by Turbidimetry. LFT was done by fully automated analyser. WIDAL was done by tube method. Blood $\mathrm{C}$ and $\mathrm{S}$ under aseptic precautions, $1 \mathrm{~mL}$ of blood was taken using sterile syringe and put into $10 \mathrm{~mL}$ of Ox Bile broth to give an optimal dilution of 1:10. Then sample was transported to microbiology lab of the hospital. In the lab, broth was incubated at $37^{\circ} \mathrm{C}$ in the incubator for 24 hours. Then subculture was done in MacConkey agar. Then appearance of pale, non-lactose fermenting colonies were looked for. If present, battery of chemical tests were done to confirm S. typhi and paratyphi growth.

After confirming growth, antibiotic sensitivity was done in Mueller-Hinton agar using Kirby-Bauer technique. A loopful of growth was taken from the agar and inoculated in peptone water. After 10 minutes, this peptone water poured over Mueller-Hinton agar to cover its entire surface. Then antibiotic discs like ampicillin, chloramphenicol, cotrimoxazole, nalidixic acid, ciprofloxacin, ofloxacin, ceftriaxone, piperacillin/ tazobactam and azithromycin are placed which was incubated for 24 hours at $37^{\circ} \mathrm{C}$. Then zone of inhibition measured and results were interpreted by Microbiologist. Culture negativity was declared only after 10 days. Microbiologist was blinded. USG Abdomen was done by ultrasound machine and CXR AP/PA View was done by digital $\mathrm{X}$-ray machine. Imaging reports were given by Radiologists and they were blinded.

Treatment Details: Ceftriaxone $(75 \mathrm{mg} / \mathrm{kg}$ ) was started as the initial drug of choice and later if there was no clinical response Ofloxacin $(10 \mathrm{mg} / \mathrm{kg})$ and/or Azithromycin $(10$ $\mathrm{mg} / \mathrm{kg}$ ) were added. Clinical outcomes like response to antibiotics and complications were assessed during hospital stay.

\section{Statistical Analysis}

All the data were statistically analysed by using SPSS (Statistical Package for the Social Sciences) software (IBMSPSS- Statistics 2014, version 22.0). Demographics, clinical and laboratory variables were given in the frequencies with their percentages and mean (SD) of various outcomes of interest as applicable. Differences in the qualitative variables were analysed using chi-square analysis. A "p" value $<0.05$ was considered as statistically significant.

\section{RESULTS/ Demography}

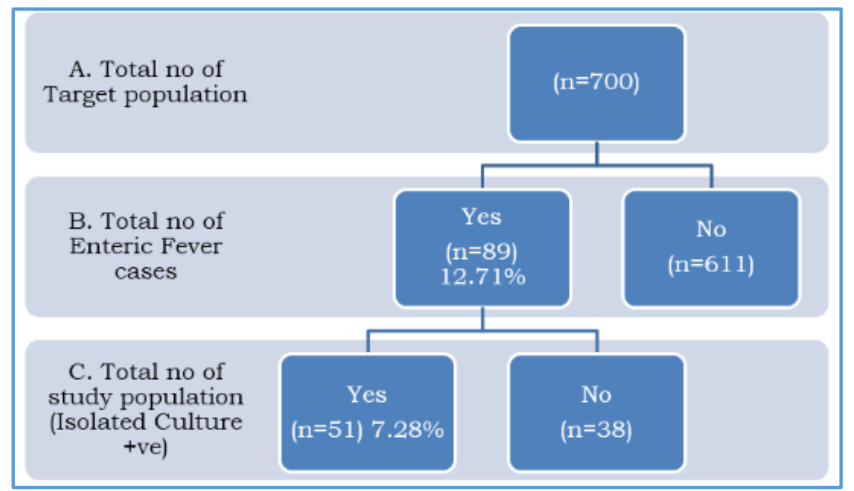

Figure 1. Number of Target Population and Study Population

\begin{tabular}{|c|c|c|c|c|c|}
\hline Age & Boys & Girls & Total & \begin{tabular}{|c|} 
Chi- \\
Square \\
Test $\left(\mathrm{X}^{2}\right)$
\end{tabular} & $\begin{array}{c}\mathbf{P} \\
\text { value }\end{array}$ \\
\hline $\begin{array}{l}6 \text { months - } \\
2 \text { years }\end{array}$ & $\begin{array}{c}3 \\
(5.88 \%)\end{array}$ & $\begin{array}{c}13 \\
(25.49 \%)\end{array}$ & $\begin{array}{c}16 \\
(31.37 \%)\end{array}$ & \multirow{4}{*}{$\begin{array}{c}1.529 \\
\text { with } 2 \\
\text { degrees } \\
\text { of } \\
\text { freedom }\end{array}$} & \multirow{4}{*}{0.46} \\
\hline $\begin{array}{c}>2 \text { years - } \\
5 \text { years }\end{array}$ & $\begin{array}{c}9 \\
(17.64 \%)\end{array}$ & $5(9.80 \%)$ & $\begin{array}{c}14 \\
(27.45 \%)\end{array}$ & & \\
\hline $\begin{array}{c}>5 \text { years - } \\
18 \text { years }\end{array}$ & $\begin{array}{c}13 \\
(25.49 \%)\end{array}$ & $\begin{array}{c}8 \\
(15.69 \%)\end{array}$ & $\begin{array}{c}21 \\
(41.18 \%)\end{array}$ & & \\
\hline Total & $\begin{array}{c}25 \\
(49.02 \%)\end{array}$ & $\begin{array}{c}26 \\
(50.98 \%)\end{array}$ & $51(100 \%)$ & & \\
\hline
\end{tabular}

Age groups were divided into three categories in our study population. More number of children 30 (58.82\%) were seen of $<5$ years of age. The distribution of total no. of boys and girls were almost equal. There was no statistically significant difference between age and sex groups $(p>0.05)$ (Table 1).

Majority of the study population were from upper middle class $58.82 \%$ (30), whereas lower middle class contributes $31.37 \%$ (16) and hardly few cases were noticed in upper class and upper-lower class i.e. 5.88\% (3) and 3.92\% (2) respectively.

In our study, $58.82 \%$ were using corporation water and $68.63 \%$ had food intake outside. 


\section{Clinical Features}

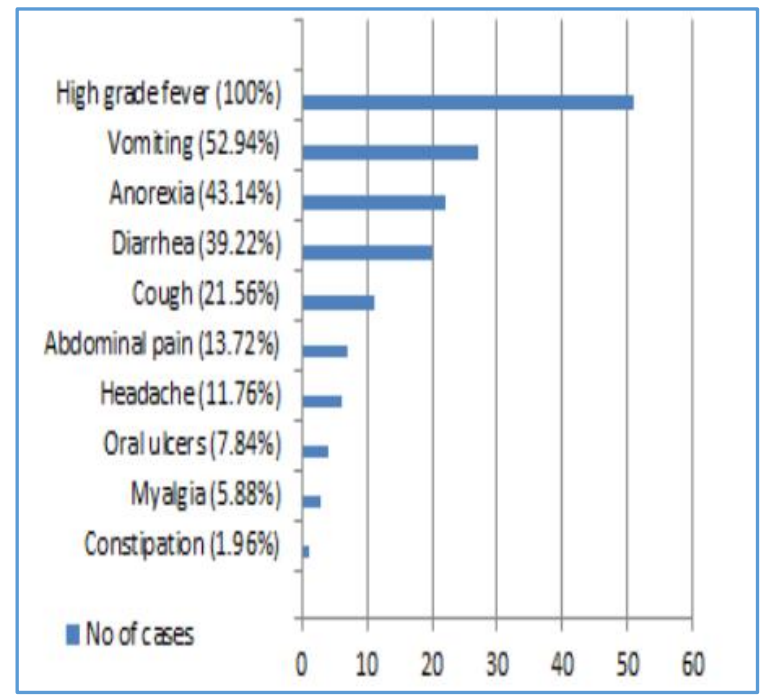

Figure 2. Symptoms among Study Population

The predominant symptoms seen are high grade fever in $51(100 \%)$, vomiting in $27(52.94 \%)$, anorexia in 22 (43.14\%) and diarrhoea in 20 (39.22\%) in the study population (Fig. 2).

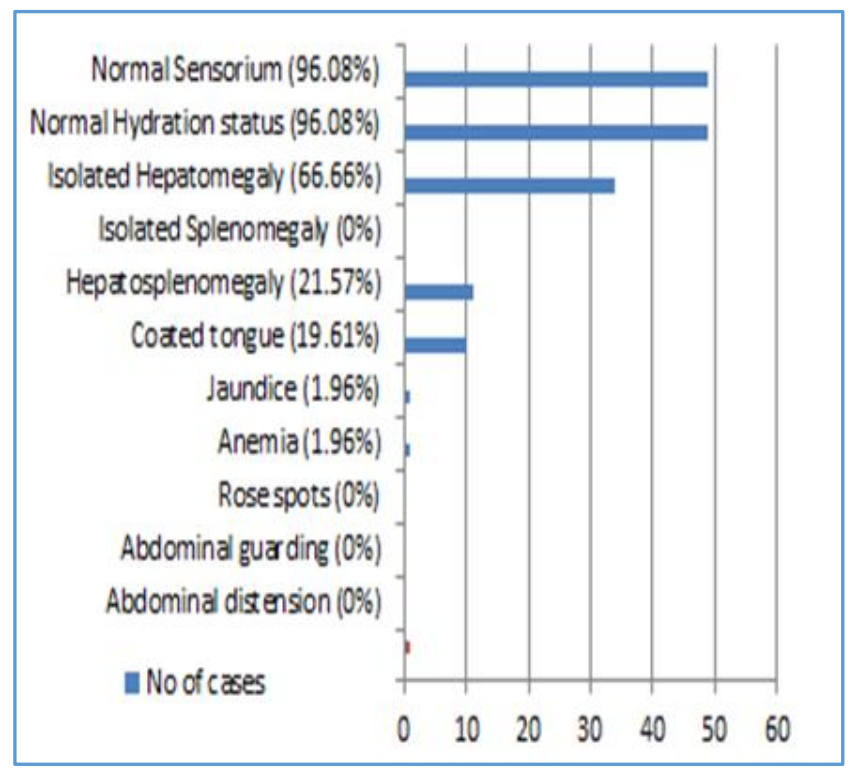

Figure 3. Signs among Study Population

The predominant signs seen are isolated hepatomegaly in $34(66.66 \%)$, hepatosplenomegaly in $11(21.57 \%)$ and coated tongue in $10(19.61 \%)$ in the study population (Fig. 3).

\section{Investigations}

Blood Culture and Sensitivity: The organism seen in majority of the blood cultures were Salmonella typhi [49 (96.08\%)], whereas Salmonella paratyphi was hardly seen [2 (3.92\%)]. The difference was found to be statistically significant $(\mathrm{p}<0.05)$.



Figure 4. Antibiotic Sensitivity Pattern of Salmonella typhi and paratyphi

Antibiotic sensitivity pattern showed ceftriaxone and piperacillin/ tazobactam were sensitive in all study population $(100 \%)$, contradictory to that all were resistant to nalidixic acid. Primary antimicrobials like ampicillin, chloramphenicol and cotrimoxazole also showed sensitivity in majority of the study population (Fig. 4).

NARST was seen in all $51(100 \%)$ children and MDRST was noticed in $1(1.96 \%)$ child. [NARST- Nalidixic Acid Resistant Salmonella typhi; MDRST- Multi Drug Resistant Salmonella typhi Resistance to all three antimicrobials (Ampicillin, Chloramphenicol and Cotrimoxazole)\}].

\begin{tabular}{|c|c|c|c|c|c|}
\hline $\begin{array}{c}\text { Haemo- } \\
\text { globin } \\
\text { Levels }\end{array}$ & $\begin{array}{c}\text { Age } \\
\text { Groups }\end{array}$ & No. & $\%$ & \begin{tabular}{|c|} 
Mean (SD) \\
Haemo- \\
globin Level \\
in the Study \\
Population
\end{tabular} & $\begin{array}{c}P \\
\text { value }\end{array}$ \\
\hline$<11 \mathrm{~g} / \mathrm{dL}$ & $\begin{array}{c}6 \text { months - } \\
5 \text { years }\end{array}$ & 22 & $43.14 \%$ & \multirow{3}{*}{$\begin{array}{c}11.24( \pm 1.42) \\
\mathrm{g} / \mathrm{dL}\end{array}$} & \multirow{3}{*}{$<0.05$} \\
\hline$<11.5 \mathrm{~g} / \mathrm{dL}$ & $\begin{array}{c}>5 \text { years - } \\
12 \text { years }\end{array}$ & 7 & $13.73 \%$ & & \\
\hline$<12 \mathrm{~g} / \mathrm{dL}$ & $>12$ years & 0 & $0 \%$ & & \\
\hline & 2. Haem & & evels & ated to Age & \\
\hline
\end{tabular}

Out of 51 children, $29(56.86 \%)$ children were found to have anaemia in the study and the most affected age group is $<5$ years (Table 2 ).

Most of the study population had normal total counts, i.e. in 39 (76.47\%), Leucocytosis in 7 (13.73\%) and Leukopenia in 5 (9.8\%), whereas normal Absolute Eosinophil Count were seen in 47 (92.16\%) and Eosinopenia in 4 (7.84\%).

Platelet counts were normal in majority of the study population [47 (92.16\%)] and few had abnormal counts like thrombocytopenia $[3 \quad(5.88 \%)]$ and thrombocytosis [1 (1.96\%)]. 
Out of 51 children, 29 (56.86\%) underwent Widal test and remaining had fever $<7$ days duration, hence not done. Overall, Widal was positive in 15 (29.41\%) children.

In this study, CRP was elevated (i.e. positive) in major population [45 (88.24\%)] and remaining were negative [6 $(11.76 \%)]$.

Out of 51, elevated SGOT and SGPT were seen in 34 $(66.67 \%)$ and $25(49.02 \%)$ children respectively.
USG abdomen was done in 22/51 (43.13\%) children and not done in remaining because of social factors. Out of 22 children 10 (45.45\%) had Isolated Hepatomegaly, 7 (31.82\%) had Hepatosplenomegaly and 5 (22.73\%) had normal USG abdomen findings.

Out of 51 children 20 (39.22\%) underwent CXR and in remaining it was not done because of social factors. Out of 20 children, 19 (95\%) had normal chest x-ray study and only 1 (5\%) had consolidation.

Treatment and Clinical Outcomes

\begin{tabular}{|c|c|c|c|c|c|c|c|c|}
\hline $\begin{array}{l}\text { IV Antibiotics } \\
\text { Received }\end{array}$ & $\begin{array}{c}\text { No. of } \\
\text { Patients }\end{array}$ & Percent & $\begin{array}{c}\text { Mean (SD) Time } \\
\text { for } \\
\text { Defervescence } \\
\text { of Fever }\end{array}$ & $\begin{array}{l}\text { Overall Mean } \\
\text { (SD) Time for } \\
\text { Defervescence } \\
\text { of Fever }\end{array}$ & $\begin{array}{c}P \\
\text { value }\end{array}$ & $\begin{array}{l}\text { Mean (SD) } \\
\text { Hospital } \\
\text { Stay } \\
\text { Duration }\end{array}$ & $\begin{array}{c}\text { Overall } \\
\text { Mean (SD) } \\
\text { Hospital } \\
\text { Stay } \\
\text { Duration }\end{array}$ & $\begin{array}{c}P \\
\text { value }\end{array}$ \\
\hline Ceftriaxone & 38 & $74.51 \%$ & $3.5( \pm 1.33)$ days & \multirow{4}{*}{$3.86( \pm 2.12)$ days } & \multirow{4}{*}{$>0.05$} & $\begin{array}{c}6.8( \pm 2.09) \\
\text { days }\end{array}$ & \multirow{4}{*}{$\begin{array}{c}6.84 \\
( \pm 2.09) \\
\text { days }\end{array}$} & \multirow{4}{*}{$>0.05$} \\
\hline $\begin{array}{c}\text { Ceftriaxone }+ \\
\text { Ofloxacin }\end{array}$ & 7 & $13.73 \%$ & $5.3( \pm 4.07)$ days & & & $\begin{array}{c}8.4( \pm 3.36) \\
\text { days }\end{array}$ & & \\
\hline $\begin{array}{l}\text { Ceftriaxone + } \\
\text { Azithromycin }\end{array}$ & 4 & $7.84 \%$ & $5.5( \pm 2.89)$ days & & & $\begin{array}{c}9.3( \pm 2.06) \\
\text { days }\end{array}$ & & \\
\hline $\begin{array}{c}\text { Ceftriaxone + } \\
\text { Ofloxacin }+ \\
\text { Azithromycin } \\
\end{array}$ & 2 & $3.92 \%$ & $2.5( \pm 0.7)$ days & & & $\begin{array}{c}6( \pm 0) \\
\text { days }\end{array}$ & & \\
\hline
\end{tabular}

In our study, ceftriaxone alone was most preferred antibiotic to treat enteric fever. In combination regime ceftriaxone was initially used, later other antibiotics were added based on poor clinical response i.e. if fever persists for more than 72 hours. There was no statistically significant difference in mean time for defervescence of fever and in mean hospital stay duration between those received ceftriaxone alone and ceftriaxone with other antibiotics (Table 3).

\begin{tabular}{|c|c|c|c|}
\hline $\begin{array}{c}\text { Clinical } \\
\text { Outcomes }\end{array}$ & No. & $\%$ & Remarks \\
\hline $\begin{array}{c}\text { Clinically } \\
\text { recovered well } \\
\text { without } \\
\text { complication }\end{array}$ & 50 & $98.04 \%$ & $\begin{array}{c}37-\text { received ceftriaxone, } \\
\text { Remaining received } \\
\text { combination of } \\
\text { antibiotics }\end{array}$ \\
\hline Complication & 1 & $1.96 \%$ & $\begin{array}{c}\text { Consolidation, } \\
\text { Recovered well after } \\
\text { treatment with } \\
\text { Ceftriaxone for 5 days }\end{array}$ \\
\hline Death & 0 & 0 & No death in our study \\
\hline \multicolumn{2}{|c|}{ Table 4. Clinical Outcomes in Our Study } \\
\hline
\end{tabular}

In this study, 37 (72.55\%) clinically recovered well without complication with the treatment of ceftriaxone alone (Table 4).

\section{DISCUSSION}

This was a prospective, observational study done between June 2016 and May 2017 at a tertiary care hospital, Puducherry. A total of 89 children had culture positive enteric fever, but only 51 were taken up for study based on inclusion and exclusion criteria.

\section{Demography}

In our study, $58.82 \%$ were $<5$ years and $31.37 \%$ were $<2$ years of age, which was supported by Sinha et al ${ }^{7}$ study from
India, who suggests that typhoid fever is common in $1-5$ years old children. Infectious Disease surveillance (IDsurv) data by Indian Academy of Paediatrics (IAP) from December 2010 - December 2013 showed 44.6\% were < 5 years and $10.7 \%$ were $<2$ years of age. ${ }^{8}$ In contrast to these findings, one Indian study by Chandrasekhar et $\mathrm{al}^{1}$ observed more number of children $(59.65 \%)$ in $>5$ years of age. There is no sex predominance seen in our study.

In our study majority of the children [30 (58.82\%)] were from upper middle class, which was similar to the study by Chandrasekhar et al $^{1}$ where 39 (75\%) were from upper middle class.

The major risk factor is food intake outside and contaminated water in the present study. Mogasale et $\mathrm{al}^{9}$ also showed contaminated water is an important risk factor in his study.

\section{Clinical Features}

In our study, the predominant symptom next to fever was vomiting seen in 27 (52.94\%) children, which was similar to the study by Chandrasekhar et $\mathrm{al}^{1}$ where $47.1 \%$ had vomiting as the predominant symptom in study population. Both Jog et $\mathrm{al}^{4}$ and Gupta et $\mathrm{al}^{3}$ also observed vomiting as the major symptom in $42 \%$ and $33.3 \%$ respectively.

Bhutta et $\mathrm{al}^{10}$ showed anorexia (70\%) as the predominant symptom next to fever, which was seen in $43.14 \%$ in our study.

The predominant examination finding was isolated hepatomegaly $34(66.66 \%)$ and hepatosplenomegaly was seen in $11(21.57 \%)$ children in the present series. Ramaswamy Ganesh et $\mathrm{al}^{6}$ had also observed that hepatomegaly was the predominant sign in their study being present in $71 \%$ of the study population. While both Chandrasekhar et $\mathrm{al}^{1}$ and Gupta et $\mathrm{al}^{3}$ observed hepatosplenomegaly as the most common sign seen in 24 (46\%) children and 42 (51.9\%) children in their studies 
respectively. None in our study had isolated splenomegaly, while Kumar et $\mathrm{al}^{2}$ showed splenomegaly as the predominant sign which was seen in 47 (44.3\%) children.

\section{Investigations/ Blood C and S Pattern}

Majority of the organism was Salmonella typhi (96.08\%) and remaining was Salmonella paratyphi A (3.92\%). All the Salmonella isolates were resistant to nalidixic acid in our study. This type of Nalidixic Acid Resistant Salmonella typhi (NARST) was also reported in the retrospective study by Vidhya Krishna et al ${ }^{5}$ in $92.9 \%$ who were resistant to nalidixic acid. Choudhary et al ${ }^{11}$ in Chennai observed $91.9 \%$ resistance to nalidixic acid. Similarly, Gupta et $\mathrm{al}^{3}{ }^{3} \mathrm{Jog}$ et $\mathrm{al}^{4}$ Chandrasekhar et al, ${ }^{1}$ Ramaswamy Ganesh et al $^{6}$ and Joshi et $\mathrm{al}^{12}$ have also observed NARST in $82.7 \%, 79 \%, 76.9 \%, 73 \%$ and $56 \%$ respectively in their studies, which seem to be significant one.

Multi Drug Resistant Salmonella typhi (MDRST) were seen in some studies like Chandrasekhar et $\mathrm{al}^{1}$ (5.8\%), Nagshetty et $\mathrm{al}^{13}(10 \%)$ and Manchanda et $\mathrm{al}^{14}$ (39\%), but contrary to that our study showed that there is an emergence of sensitivity to these primary antimicrobials like Ampicillin (98.04\%), Chloramphenicol (98.04\%) and Cotrimoxazole (98.04\%). MDRST was seen in 1 (1.96\%) children in our study. Studies by Jog et $\mathrm{al}^{4}{ }^{4}$ Gupta et $\mathrm{al}^{3}$ and Joshi et al ${ }^{12}$ have also supported our findings of sensitivity to primary antimicrobials.

The important aspect with respect to antibiotic sensitivity in our study was the sensitivity of the culture to ceftriaxone in all the culture positive children. This is similar to the observations by Chandrasekhar et al, ${ }^{1}$ Gupta et al, ${ }^{3}$ Jog et $\mathrm{al}^{4}{ }^{4}$ Chowta et al, ${ }^{15}$ Singh et al ${ }^{16}$ and Malla et al ${ }^{17}$ studies.

In addition to that, in our study all Salmonella isolates were sensitive to piperacillin-tazobactam. No studies were mentioned about this drug.

\section{Other Laboratory Findings}

Anaemia was more in Umar et $\mathrm{al}^{18}$ study which showed $69.2 \%$, in our study it was $45.1 \%$. Other studies showed lesser proportion than our study as follows: Yaramis et $\mathrm{al}^{19}$ (38\%), Chandrasekhar et $\mathrm{al}^{1}$ (34.6\%) and Gupta et $\mathrm{al}^{3}$ (10\%).

In our study, WBC counts were normal in $76.47 \%$. Remaining had WBC count abnormalities, among that leucocytosis $(13.73 \%)$ were seen > leukopenia (9.80\%). This is similar to the observations on culture positive enteric fever by Ramaswamy Ganesh et al ${ }^{6}$ [Leucocytosis (12\%) > leukopenia (8\%)], Umar et $\mathrm{al}^{18}$ [Leucocytosis (15.4\%) > leukopenia (2\%)] and Singh et al ${ }^{16}$ [leucocytosis (15.9\%) > leukopenia (12\%)].

Eosinopenia was present in $7.84 \%$ in our study, which was < the previous studies by Jog et $\mathrm{al}^{4}$ and Ramaswamy Ganesh et al, ${ }^{6}$ who observed eosinopenia in $76.9 \%$ and $72 \%$ respectively.

Thrombocytopenia in our study $(5.88 \%)$ is < that observed by Jog et $\mathrm{al}^{4}(25.9 \%)$, Gupta et $\mathrm{al}^{3}$ (14.8\%) and Yaramis et $\mathrm{al}^{19}(10 \%)$. But in our study thrombocytosis was present in one child (1.96\%) who had iron deficiency anaemia and also none of the previous studies had shown this feature.

Widal was positive in 15 (51.72\%) of the 29 who had undergone the test. This is similar to that of other studies by Gupta et $\mathrm{al}^{3}(43.2 \%)$, Jog et $\mathrm{al}^{4}(48.4 \%)$ and Singh et $\mathrm{al}^{16}$
(50.7\%), whereas Kumar et $\mathrm{al}^{2}$ (68.9\%), Malla et $\mathrm{al}^{17}$ (83\%) and Chowta et al15 $(88.6 \%)$ had shown high percentage of Widal positivity.

In our study, elevated CRP was seen in 46 (90.20\%) children, whereas no studies mentioned about CRP.

Elevated SGOT (66.66\%) was seen $>$ the elevated SGPT $(49.02 \%)$ in our study. Similar findings were observed by Chandrasekhar et al, ${ }^{1}$ who showed elevated SGOT (73\%) > elevated SGPT $(69.2 \%)$ and Yaramis et $\mathrm{al}^{19}$ also showed raised level of SGOT (61.3\%) > the raised level of SGPT (48.4\%). This is contrast to Jog et $\mathrm{al}^{4}$ and Gupta et $\mathrm{al}^{3}$ have showed SGPT was elevated in $43 \%$ and $31 \%$ respectively, which were $>$ elevated SGOT.

USG Abdomen done in 22/51 children, it showed isolated hepatomegaly in $10(45.45 \%)$ and hepatosplenomegaly in 7 $(31.82 \%)$ in our study. Gall bladder abnormalities were not seen in our study in contrast to Ramaswamy Ganesh et al ${ }^{6}$ study, wherein USG Abdomen revealed gallbladder (GB) hydrops in 6 children, thickening in 8 children, GB sludge in 1 and free fluid abdomen in 13 children.

In our study, CXR was done in 20/51. It showed normal study in 19 (95\%) and consolidation in 1 (5\%). No studies mentioned about CXR findings.

\section{Treatment and Clinical Outcomes}

In the management of enteric fever in our study ceftriaxone was the initial antibiotic of choice in $74.51 \%$, which is similar to that of Gupta et $\mathrm{al}^{3}$ series. But Jog et $\mathrm{al}^{4}$ showed only $62.1 \%$ of children had ceftriaxone as the initial antibiotic of choice.

Among the combination of antibiotics, 7 (13.73\%) children received both ceftriaxone and ofloxacin as the initial antibiotics in our study, while 4 (7.84\%) children received both ceftriaxone and azithromycin. Jog et $\mathrm{al}^{4}$ study had shown the slightly higher usage of combination of ceftriaxone and azithromycin in 16 patients (13.4\%).

In our study, azithromycin was added if fever and toxicity persisted even 72 hours after initiation of ceftriaxone.

All three antibiotics (ceftriaxone, ofloxacin and azithromycin) were given in 2 (3.92\%) children in our study. In these 2 children, both ceftriaxone and ofloxacin were started initially and later because of persisting toxicity and fever spikes $>5$ days azithromycin was added.

Overall, mean (SD) time taken for defervescence of fever was $3.86( \pm 2.12)$ days in our study, which was almost similar to that of Malla et al ${ }^{17}$ where mean time for defervescence was 4.7 days.

In our study, mean (SD) time taken for defervescence of fever to ceftriaxone alone was $3.5( \pm 1.33)$ days. The mean time to defervescence when ceftriaxone alone was used as therapy in Jog et $\mathrm{al}^{4}$ Gupta et $\mathrm{al}^{3}$ and Malla et $\mathrm{al}^{17}$ were 4.2 days, 4.3 days and 5 days respectively.

In our study, combination treatment in children treated with ceftriaxone and ofloxacin had the mean (SD) time for defervescence as $5.3( \pm 4.07)$ days with ceftriaxone and azithromycin it was $5.5( \pm 2.89)$ days, whereas in children who received all 3 antibiotics (ceftriaxone, ofloxacin and azithromycin) it was $2.5( \pm 0.7)$ days.

Parry et $\mathrm{al}^{20}$ observed fever clearance times for fluoroquinolones, third generation cephalosporins and azithromycin as 4 days, 7 days and 4 to 6 days respectively. 
Overall, mean (SD) hospital stay was $6.84( \pm 2.09)$ days in our study. The available studies have not mentioned about the total number of hospital stay days.

In our study only one patient had consolidation and recovered with ceftriaxone, whereas Singh et al ${ }^{16}$ observed 4 cases had pneumonia as the complication in his study.

No other complications were noted in our study during the hospital stay. Gastrointestinal complications were observed in Gupta et al $^{3}$ study who showed melena in 6 children (7.5\%) and Kumar et $\mathrm{al}^{2}$ also observed gastrointestinal bleed with perforation in one patient in his study. Bhutta et $\mathrm{al}^{10}$ showed intestinal perforation in $0.5 \%$.

There was no death in our study, while Parry et $\mathrm{al}^{20}$ and Chowta et $\mathrm{al}^{15}$ showed death in their studies.

\section{CONCLUSION}

In our study, $58.82 \%$ were $<5$ years. High grade fever, vomiting, anorexia and diarrhoea were the common symptoms. Isolated hepatomegaly and hepatosplenomegaly were the common signs. Enteric fever should be suspected when there is high CRP, normal WBC and platelet counts in a child with $\geq 3$ days fever with isolated hepatomegaly/ hepatosplenomegaly. Blood culture is the gold standard diagnostic test. Salmonella typhi was the major isolate. Antibiotic sensitivity pattern showed re-emergence of strains with high sensitivity to first line antibiotics like Ampicillin, Chloramphenicol and Cotrimoxazole. Nalidixic acid resistance was observed in all isolates. All the cultures were sensitive to Ceftriaxone and it was used as first line intravenous antibiotic for enteric fever with good outcome. Only one complication (consolidation) and no death were seen in our study.

\section{ACKNOWLEDGEMENTS}

I sincerely thank Prof. Dr. V. D. Raghavendran M.D., D.C.H, Head of the Department, Paediatrics Department, SLIMS, for his support and guidance towards the completion of my study.

\section{REFERENCES}

[1] Chandrashekar, Anilkumar YC, Sodhi K, et al. Study of clinical and laboratory profile of enteric fever in pediatric age group. Int J Basic and Applied Med Sci 2013;3(3):16-23.

[2] Kumar A, Pandit V, Shetty S, et al. Study of clinical profile and antibiotic sensitivity pattern in culturepositive typhoid fever cases. Indian J Community Med 2012;37(4):256-8.

[3] Gupta S, Handa A, Chadha DS, et al. Profile of culture positive enteric fever from Bangalore. Med J Armed Forces India 2009;65(4):328-31.

[4] Jog S, Soman R, Singhal $T$, et al. Enteric fever in Mumbai - clinical profile, sensitivity patterns and response to antimicrobials. J Assoc Phy India 2008;56:237-40.
[5] Krishna V, Venkatramanan P, Rajendran P. Enteric fever in children below 2 year - need for an effective conjugate vaccine? Indian J Pediatr 2014;81(5):511.

[6] Ganesh R, Janakiraman L, Vasanthi T, et al. Profile of typhoid fever in children from a tertiary care hospital in Chennai-South India. Indian J Pediatr 2010;77(10):1089-92.

[7] Sinha A, Sazawal S, Kumar R, et al. Typhoid fever in children aged less than 5 years. Lancet 1999;354(9180):734-7.

[8] Infectious Disease Surveillance. www.idsurv.org 2013.

[9] Mogasale V, Maskery B, Ochiai RL, et al. Burden of typhoid fever in low-income and middle-income countries: a systematic, literature-based update with risk-factor adjustment. Lancet Glob Health 2014;2(10):e570-e80.

[10] Bhutta ZA. Enteric fever (Typhoid Fever). In: Kleigman RM, Stanton BF, St.Geme JW, et al. eds. Nelson textbook of paediatrics. 19th edn. Philadelphia: Elsevier/Saunders Publications 2012:954-8.

[11] Choudhary A, Gopalakrishnan R, Nambi PS, et al. Antimicrobial susceptibility of Salmonella enteric serovars in a tertiary care hospital in southern India. Indian J Med Res 2013;137(4):800-2.

[12] Joshi BG, Keyal K, Pandey R, et al. Clinical profile and sensitivity pattern of Salmonella serotypes in children: a hospital based study. J Nepal Paediatr Soc 2011;31(3):180-3.

[13] Nagshetty K, Channappa ST, Gaddad SM. Antimicrobial susceptibility of Salmonella Typhi in India. J Infect Dev Ctries 2010;4(2):70-3.

[14] Manchanda V, Bhalla P, Sethi M, et al. Treatment of enteric fever in children on the basis of current trends of antimicrobial susceptibility of Salmonella enteric serovar typhi and paratyphi A. Indian J Med Microbiol 2006;24(2):101-6.

[15] Chowta MN, Chowta NK. Study of clinical profile and antibiotic response in typhoid fever. Indian J Med Microbiol 2005;23(2):125-7.

[16] Singh SD, Shrestha S, Shrestha N, et al. Enteric fever in children at Dhulikhel hospital. J Nepal Paediatr Soc 2012;32(3):216-20.

[17] Malla T, Malla KK, Thapalial A, et al. Enteric fever: a retrospective 6-year analysis of 82 paediatric cases in a teaching hospital. Kathmandu Univ Med J 2007;5(2):181-7.

[18] Umar LW, Adelaiye H, Adebiyi M, et al. Typhoid fever in children presenting to paediatric medical wards of Ahmadu Bello University Teaching Hospital Zaria: a 13-months review. Niger J Paed 2013;40(3):211-6.

[19] Yaramis A, Yildirim I, Katar S, et al. Clinical and laboratory presentation of typhoid fever. J Int Pediatr 2001;16(4):227-31.

[20] Parry CM, Hien TT, Dougan G, et al. Typhoid fever. N Engl J Med 2002;347(22):1770-82. 